\title{
Cultured growth hormone transgenic salmon are reproductively out-competed by wild-reared salmon in semi-natural mating arenas
}

\author{
John L. Fitzpatrick ${ }^{\mathrm{a}, 1}$, Hamid Akbarashandiz ${ }^{\mathrm{a}}$, Dionne Sakhrani ${ }^{\mathrm{a}}$, Carlo A. Biagi ${ }^{\mathrm{a}}$, \\ Trevor E. Pitcher ${ }^{b}$, Robert H. Devlin ${ }^{\mathrm{a}, *}$ \\ a Fisheries and Oceans Canada, 4160 Marine Drive, West Vancouver, B.C. V7W 1N6, Canada \\ ${ }^{\mathrm{b}}$ Department of Biological Sciences, University of Windsor, Windsor, Ontario N9B 3P4, Canada
}

\section{A R T I C L E I N F O}

\section{Article history:}

Received 18 May 2010

Received in revised form 26 October 2010

Accepted 29 November 2010

Available online 2 December 2010

\section{Keywords:}

Aquaculture

Ecological impact

Genetic modification

Genetically engineered organisms

Sperm competition

\begin{abstract}
A B S T R A C T
The production of growth hormone $(\mathrm{GH})$ transgenic animals has raised a host of social and scientific concerns regarding their potential impacts on ecosystems should they escape into nature. Indeed, theoretical models suggest that GH transgenic animals could, under specific conditions, decimate local populations. However, while there are numerous laboratory examinations of factors affecting survival of transgenic and wild animals, we know little about the competitive reproductive capacity of transgenic animals. Here, we examined the reproductive capabilities of cultured GH transgenic coho salmon (Oncorhynchus kisutch) when in competition with wild coho derived from nature using semi-natural mating arenas (within a contained facility). To account for the well-known reproductive impairments associated with culturing salmon in laboratory facilities we contrasted the competitive reproductive success of $\mathrm{GH}$ transgenic coho against that of cultured non-transgenic coho. We also performed in vitro sperm analyses to assess the postcopulatory competitive ability of GH transgenic coho. In competitive mating arenas, transgenic coho performed fewer courtship and aggressive behaviours than coho from nature and sired less than $6 \%$ of offspring. Non-transgenic cultured coho, despite their smaller body size, sired more than twice as many offspring than transgenic coho when competing against wild coho in mating arenas. Transgenic males also face a postcopulatory reproductive disadvantage as their ejaculates contained fewer sperm that swam slower and for shorter durations than sperm from wild males. Together, these findings suggest limited potential for the transmission of transgenes from cultured GH transgenic coho salmon through natural matings should they escape from a contained culture facility into nature and reproductively interact with a local wild coho salmon strain. However, as responses of wild-reared fish can differ greatly from those of cultured fish, we stress the importance of understanding genotype-by-environment interactions for reproductive phenotypes when developing risk assessment information.
\end{abstract}

(c) 2011 Elsevier B.V. All rights reserved.

\section{Introduction}

Although the use of transgenic organisms is prevalent in laboratory and plant agricultural settings, concerns persist regarding the potential ecological impacts these organisms may cause should they enter into natural ecosystems (Tatar, 2000; Snow et al., 2005; Devlin et al., 2006; Kapuscinski et al., 2007). For animals, genetic engineering efforts have historically focused on the production of fast-growing transgenic animals with growth hormone $(\mathrm{GH})$ gene constructs inserted into their genome (Pursel et al., 1989; Devlin et al., 2006). GH transgenic mammals have shown limited responses to date, whereas GH transgenic fish can grow at dramatically accelerated rates

\footnotetext{
* Corresponding author.

E-mail address: robert.devlin@dfo-mpo.gc.ca (R.H. Devlin).

1 Current address: Centre for Evolutionary Biology, School of Animal Biology, University of Western Australia, WA 6009, Australia.
}

and convert feed more efficiently than their genetically wild counterparts making them of particular interest for commercial production (Du et al., 1992; Fu et al., 1998; Martinez et al., 1996; Rahman et al., 1998; Venugopal et al., 2004; Devlin et al., 2004a). However, GH transgenic animals also can possess significant behavioural and physiological changes such as enhanced appetite, feeding motivation and competitive ability (Abrahams and Sutterlin, 1999; Devlin et al., 1999; Devlin et al., 2004b; Sundström et al., 2004) which impart the theoretical potential to pose ecological risks to natural ecosystems (even beyond those described for aquaculture strains) should they escape or be released into the wild (Devlin and Donaldson, 1992; Kapuscinski and Hallerman, 1991; Muir and Howard, 1999; Hindar et al., 2006; Kapuscinski et al., 2007). In particular, GH transgenic fish might facilitate the extinction of a locally adapted wild population, if transgenic fish have poorer offspring viability but greater reproductive success, because transgenic fish are preferred as mates and/or are more successful in intraspecific competition, than their wild relatives 
(Muir and Howard, 1999). Yet, despite the potential risks posed by transgenic animals, information on their reproductive capacity is limited (Dunham et al., 1995; Howard et al., 2004; Bessey et al., 2004).

Fast-growing GH transgenic coho salmon (Oncorhynchus kisutch) are a useful model for assessing the reproductive capacity and accompanying ecological risks of producing highly mobile transgenic animals. GH transgenic coho salmon grow 11 times larger (on average) than non-transgenic fish in their first year (Devlin et al., 1994), but achieve similar adult body sizes as wild-reared coho and reach sexual maturity in 2 years rather than the 3 years necessary for wild fish (coho salmon are semelparous and die after maturation) (Devlin et al., 2004a). When housed with non-transgenic coho, transgenics are better able to sequester food resources (Devlin et al., 1999), but can have reduced offspring survival (Devlin et al., 2004a), disease resistance (Jhingan et al., 2003) and swimming abilities compared with wild-reared fish (Farrell et al., 1997). Transgenic coho may also be reproductively disadvantaged. Using pair-wise competitive matings in artificial spawning chambers and in vitro fertilization trials, Bessey et al. (2004) demonstrated that wild coho males were socially dominant and perform more courtship behaviours than transgenic coho when competing for females. However, when in competition, sperm from laboratory-derived transgenic males fertilized equal numbers of eggs as sperm from wild males (Bessey et al., 2004). Therefore, it remains unclear if wild coho would monopolize reproduction when multiple fish interact simultaneously in more natural conditions where fish are allowed to exercise full mate choice as in the wild. Further, whether sperm quality from transgenic males is fully equivalent to that of wild males is not well known.

In this study, we examined the mating success of cultured $\mathrm{GH}$ transgenic coho when in direct competition for breeding opportunities with wild coho in semi-natural mating arenas. Our approach differs from previous work, which examined pair-wise competitive reproductive success of transgenic, cultured and wild salmon in artificial stream channels (Bessey et al., 2004), by allowing multiple fish to interact in a semi-natural spawning arena that allows fish to exercise mate choice and reproductive success to be influenced by intra- and intersexual competition. Thus, these experiments most parallel a hypothetical scenario where cultured transgenic fish have escaped from a contained culture facility into nature where they are able to reproductively interact with a local wild coho salmon strain. However, a necessary precaution when working with transgenic salmon is that they are permanently maintained in land-based (tank) rearing facilities. Yet rearing fish in culture can lead to a host of behavioural and physiological differences between cultured fish and their wild relatives (e.g. Devlin et al., 2004a; Bessey et al., 2004; Fleming and Gross, 1993; Fleming et al., 2000; Berejikian et al., 2001; Sundström et al., 2007). To account for these culture effects we first assessed the competitive reproductive success of cultured non-transgenic salmon in competition with wild salmon. We then examined the spawning ability of cultured GH transgenic salmon when in competition with wild coho to assess the effects of $\mathrm{GH}$ transgenesis on competitive reproductive success. Finally, we examined if transgenic salmon are disadvantaged during postcopulatory sperm competition by contrasting ejaculate quality of transgenic and wild coho.

\section{Methods}

\subsection{Fish stocks and experimental arenas}

Experiments were performed from January 27 to February 10, 2006 (Experiment 1: cultured vs. wild salmon) and January 23 to February 3 , 2003 (Experiment 2: transgenic vs. wild salmon) at Fisheries and Oceans Canada's Centre for Aquaculture and Environmental Research, British Columbia, in accordance with the requirements established by the Canadian Council for Animal Care. Fish used in the experiments were obtained or derived (Devlin et al., 2004b) from wild-type coho salmon from the Chehalis River (southwestern British Columbia) and fall into three strains; 1 ) hatchery fish (termed wild-type in this study): mature, three-year-old, hatchery-bred salmon that were reared as juveniles in fresh water, released to the wild as smolts for their marine phase, and returned to spawn upon reaching maturity, were transported in late December from the Chehalis River Hatchery to the laboratory, 2) cultured fish: mature, laboratory-reared, three-yearold non-transgenic salmon derived from 10 single-pair crosses of Chehalis River parents, and 3) transgenic fish: mature laboratoryreared two-year-old transgenic, growth-enhanced $(\mathrm{GH})$ salmon, hemizygous for the transgene, generated from crosses between wild-caught females and males homozygous for the transgene (see Devlin et al., 1994, 2004a; Bessey et al., 2004 for additional details on the transgenic line used in this study). Because transgenic fish, with their faster growth, mature at a younger age than wild fish, and because coho salmon are semelparous and die after maturation, it is not possible to age-match transgenic fish to other groups used in these experiments. Cultured and transgenic fish were incubated and raised in fresh well water until smoltification, and were then reared in filtered, oxygenated seawater. Upon reaching maturation, fish were returned to fresh well water conditions.

\subsection{Part I: competitive spawning experiments}

Competitive spawning trials were performed in two identically constructed semi-natural mating arenas each stocked with 16 fish (arenas A and B). In Experiment 1, 8 cultured coho competed with 8 wild coho and in Experiment 2, 8 transgenic coho competed with 8 wild coho ( 4 males and females of each genetic background). Arenas were $4.88 \mathrm{~m}$ in diameter, with an inner $0.91 \mathrm{~m}$ circular obstruction placed at the centre of the arena. Gravel (size range 1-10 cm) was placed in the arenas $(\sim 15-20 \mathrm{~cm}$ depth), providing a total available spawning area of $18.05 \mathrm{~m}^{2}$ or $1.13 \mathrm{~m}^{2} /$ fish, a value within the range typically used by spawning female coho (Burner, 1951) that promotes competition for spawning sites (Fleming and Gross, 1993). Fish interacted in water $18-20 \mathrm{~cm}$ deep. The water flow rate was measured with a FLO-MATE 2000 (Marsh-McBirney Inc.) and maintained at $1 \mathrm{~cm} / \mathrm{s}$ (edge of the inner circular obstruction) to $16 \mathrm{~cm} / \mathrm{s}$ (outer edge of the arena) by submersible pumps. Fish were maintained at a 10:14 light:dark cycle, which closely matches the normal length of natural light exposure during January and February at our study site. Fish were labeled by surgically affixing plastic tags of different shapes and colours to the base of their dorsal fin, which allowed differentiation between genetic backgrounds and sexes during behavioural observations. Prior to all handling and sampling procedures fish were anaesthetized in MS-222 (100 mg/L plus $200 \mathrm{mg} / \mathrm{L}$ sodium bicarbonate). Fish were only used in these experiments if they were fully mature (i.e. running milt for males, and completely ovulated eggs for females). Fish were allowed to spawn naturally and arenas were only disturbed when mortalities were removed (coho salmon die after reaching sexual maturity). After removal, mortalities were weighed $(\mathrm{g})$, measured $(\mathrm{cm})$, dissected, and gonad mass recorded ( $\mathrm{g}$ ). Once all experimental fish had died the spawning arenas were left undisturbed to allow fertilized eggs to develop and fry to emerge from the gravel at which time they were collected for genetic analysis.

\subsubsection{Pedigree analyses}

Microsatellite genotyping and pedigree analysis of parents and progeny were performed to assess the reproductive fitness of individual parents within a spawning experiment. DNA was extracted from parental (alcohol preserved liver tissue) and progeny (using a blood sample placed in $100 \mu \mathrm{L}$ of $0.01 \mathrm{M} \mathrm{NaOH}$, heated at $90{ }^{\circ} \mathrm{C}$ for 10 min to inactivate enzyme activity or from frozen cross section of body) fish using either a Qiagen ${ }^{\circledR}$ DNeasy Kit following manufacturer's instructions for parents or a simple lysis method for progeny 
(Devlin et al., 2004b). In Experiment 1, 3936 offspring from competitive spawnings between wild and cultured salmon were individually genotyped to determine parentage. In contrast, in Experiment 2, rather than initially determining paternity for offspring generated from competitive spawnings between wild and transgenic salmon we first tested 3102 offspring for the presence of the GH transgene using real time (RT) polymerase chain reaction (PCR) procedures. RT PCR was performed using an ABI Prism ${ }^{\mathrm{TM}} 7000$ Sequence Detection System, Version 1.0.1 (Applied Biosystems, Foster City, CA). Primers and TaqMan-MGB ${ }^{\mathrm{TM}}$ probes were designed using ABI Primer Express software (Applied Biosystems, Foster City, CA). Primers used to amplify the transgene during RT PCR were MT forward primer (MT 100) (5'-AAGCGCGATCGAAAAGGA-3') and MT reverse primer (GH 100) (5'-GGCTTACCTTGTCCCATTTTTACTC-3'). The MTH3GH probe sequence was $5^{\prime}$-CCCATCCTTGGCAATT-3'. Primers designed from insulin-like growth factor-1 (IGF-1), a constitutively expressed gene, were used as a genetic control to ensure amplifiable template was available. Primers used as a genetic control during RT PCR were IGF1-F forward primer (5'-TGCGATGTGCTGTATCTCCTGTA-3') and IGF1-R reverse primer (5'-CCTGTTGCCGCCGAAGT-3'). The IGF1 probe sequence was $5^{\prime}$-TCTCACTGCTGCTGTGC-3'. Multiplexed reactions were carried out in 96-well plates using $20 \mu \mathrm{L}$ volume per well, including $20 \mathrm{mM}$ Tris- $\mathrm{HCl}$ (pH 8.4), $50 \mathrm{mM} \mathrm{KCl}, 0.2 \mathrm{mM}$ each dNTP, $1.5 \mathrm{mM} \mathrm{MgCl} 2,150 \mathrm{nM}$ MT-1 primer, $150 \mathrm{nM} \mathrm{GH}-1$ primer, $50 \mathrm{nM}$ MTGH probe, 300 nM IGF1-1 primer, 300 nM IGF1-2 primer, 100 nM IGF-1 probe, 0.05 units Taq DNA polymerase, and $1.0 \mu \mathrm{L}$ template. Thermal cycling conditions for RT PCR were performed at $50{ }^{\circ} \mathrm{C}$ for $2 \mathrm{~min}, 95^{\circ} \mathrm{C}$ for $10 \mathrm{~min}$, and 40 cycles of $95^{\circ} \mathrm{C}$ for $15 \mathrm{~s}$ (denaturing) and $60{ }^{\circ} \mathrm{C}$ for $1 \mathrm{~min}$ (annealing/extension). Each plate included a positive and negative control.

For pedigree analyses we examined up to 5 microsatellite loci, including OMM 1128, OMM 1231, OMM 1270, OTS 101 and OTS 103 (Small et al., 1998; Rexroad et al., 2001; Rexroad and Palti, 2003), which were amplified using fluorescent primers (Applied Biosystems, Foster City, CA). PCR reactions were conducted in 96-well plates using a GeneAmp® PCR system 2700 thermal cycler (Applied Biosystems, Foster City, CA) using $25 \mu \mathrm{L}$ volume per well, including $20 \mathrm{mM}$ Tris- $\mathrm{HCl}$ (pH 8.4), $50 \mathrm{mM} \mathrm{KCl}, 0.08 \mathrm{mM}$ each dNTP, $2 \mathrm{mM} \mathrm{MgCl}_{2}, 0.1 \mu \mathrm{M}$ forward primer, $0.1 \mu \mathrm{M}$ reverse primer, 1 unit Taq DNA polymerase, and $2.0 \mu \mathrm{L}$ template. Thermal cycling conditions for OTS primers were $95{ }^{\circ} \mathrm{C}$ for $12 \mathrm{~min}, 10$ cycles of $94{ }^{\circ} \mathrm{C}$ for $15 \mathrm{~s}$ (denaturing), $55^{\circ} \mathrm{C}$ for $15 \mathrm{~s}$ (annealing), $72{ }^{\circ} \mathrm{C}$ for $15 \mathrm{~s}$ (extension), 20 cycles of $89^{\circ} \mathrm{C}$ for $15 \mathrm{~s}$ (denaturing), $55^{\circ} \mathrm{C}$ for $15 \mathrm{~s}$ (anneal), $72{ }^{\circ} \mathrm{C}$ for $15 \mathrm{~s}$ (extension), and $72{ }^{\circ} \mathrm{C}$ for $10 \mathrm{~min}$. Conditions for OMM primers were $94^{\circ} \mathrm{C}$ for $5 \mathrm{~min}, 35$ cycles of $94^{\circ} \mathrm{C}$ for $30 \mathrm{~s}$ (denaturing), $58^{\circ} \mathrm{C}$ for $30 \mathrm{~s}$ (annealing), $72{ }^{\circ} \mathrm{C}$ for $1 \mathrm{~min}$ (extension) and finished off with $72{ }^{\circ} \mathrm{C}$ for $7 \mathrm{~min}$.

After amplification, $1 \mu \mathrm{L}$ from each of the PCR products was added either to $12 \mu \mathrm{L}$ deionized formamide and $0.5 \mu \mathrm{L}$ Gene Scan Rox size standard (in 2003) or a mixture of $20 \mu \mathrm{L}$ of Hi-Di Formamide and $1 \mu \mathrm{L}$ of GS-LIZ500 (in 2006) (all reagents from Applied Biosystems). The PCR products were then sized and detected using an ABI Prism 310 Gene Scan v. 3.1 (in 2003) or an Applied Biosystems 3130x Genetic Analyzer (in 2006).

In Experiment 1, we identified the wild and cultured salmon parents of all the offspring genotyped. In Experiment 2, we identified the wild and transgenic parents of all offspring that tested positive for the transgene. Because transgenic fish were hemizygous for the transgene, we assumed there were an equal number of offspring that did not test positive for the transgene as there were offspring that tested positive for the transgene (Bessey et al, 2004; Devlin et al., 2004a). All other fish that did not test positive for the transgene were assumed to be the product of matings between wild fish as the transgenic detection failure rate with this assay is $0.12 \%$ (Devlin et al., 2004a). Offspring were assigned to one of four possible parental cross categories using WhichParents (Bodega Marine Laboratory, University of California Davis), a program that calculates allelic combinations based on all possible parental crosses and then assigns offspring to their parents by identifying which parents could have produced that offspring. In both experiments, we assumed that the egg-to-fry survival of all strains is equal and their proportions reflect the spawning and fertilization success of their parents. However, our estimation of transgenic reproductive success is conservative, as we intentionally did not account for the lowered fertilization and survival ability of transgenics (Devlin et al., 2004a).

\subsubsection{Behavioural observations}

To complement the genetic pedigree data, observations on the spawning behaviour of fish in each experiment were performed. Two 5-min behavioural observations were performed each day in the morning (8:30-11:30 $\mathrm{h}$ ) and afternoon (16:00-17:30 h). The number of behaviours per strain (not individual) was recorded at each observation period. Both males and females performed chase behaviours resulting in displacement of conspecifics. The sum of all chase behaviours was used as an index of aggression for males and females. Female courtship was defined as the sum of all digging, covering and gape behaviours, while the sum of all attending, quivering and gape behaviours was used as an index of male courtship (for additional information on salmon courtship behaviours see Bessey et al., 2004). Behaviours were observed directly in Experiment 1 and were analyzed from video recordings in Experiment 2. Although fish were identified to individual using barcode marks on tags, these marks could not always be reliably identified underwater (particularly on overcast days) and thus behaviours were scored as sums to the level of sex and strain.

For both experiments, fish were handled in the same way prior to the experiments and the physical layout of the mating arenas was identical. Throughout both experiments, we performed routine, twice-daily, observations of the mating arenas to monitor fish health and check for mortalities. Therefore, while behavioural observations were observed directly in Experiment 1 and were determined from video recordings in Experiment 2, fish in the mating arenas experienced similar exposure to human observers in both experiments.

\subsection{Part II: sperm quality of transgenic and wild salmon}

Sperm quality was assessed from 8 wild and 7 transgenic males from the same cohort as the fish assessed in the competitive spawning experiment above (Experiment 2). Fish were anaesthetized in MS-222 as above, their ventral surface was wiped dry to avoid contamination with mucus and water, and milt (sperm and seminal plasma) was collected by applying gentle pressure to the male's abdomen. Sperm density was determined by placing subsamples of milt in two capillary tubes, centrifuging tubes for $10 \mathrm{~min}$ in a microhaematocrit centrifuge, and determining a mean spermatocrit value, which indicates the proportion of packed sperm in a volume of milt (Hoysak and Liley, 2001). Sperm motility was measured by recording actively swimming sperm under a pre-focused microscope (100× magnification) following the protocols described in Hoysak and Liley (2001). Sperm velocity was determined from video recordings by measuring the linear path distance each sperm traveled with in the field of view divided by the duration it was tracked (Pitcher et al., 2007). We focused our velocity analyses on sperm curvilinear velocity (VCL) as this measure is correlated with fertilization success in other salmonid species (e.g. Arctic charr, Salvelinus alpinus, Liljedal et al., 2008). VCL was assessed at $10 \mathrm{~s}$ after sperm activation as the majority of eggs are fertilized within the first $10 \mathrm{~s}$ of sperm-egg interaction in salmonids (Hoysak and Liley, 2001). Sperm longevity was measured as the duration of time required for $>95 \%$ of sperm to cease forward movement (Gage et al., 2002).

\subsection{Statistical analyses}

Analyses were performed using JMP (version 7.0.1, SAS Institute Inc. 2007). Data were tested for normality, transformed when necessary, and nonparametric statistics were applied when the 
conditions of normality were not met. We assessed if log body mass differed between sexes and strains using two-way ANOVAs followed by Tukey-Kramer post hoc tests. We only present comparisons of body mass between strains because body mass and standard lengths were significantly related across all fish (linear regression, $r=0.91$, $\mathrm{p}<0.001$ ). Additionally, body mass is a useful measure to compare between strains because previous studies have linked competitive reproductive behaviours with body mass in salmon (e.g. Fleming and Gross, 1993). Survival times were compared between competing strains using a proportional hazard model that examined the effects of replicate arena, sex and strain on survival. Since behaviours were recorded for strains, not individuals, we were unable to incorporate individual variability into our analyses. Therefore, we assessed behavioural difference between strains using two-tailed binomial tests, approximated using a z-distribution, comparing if wild fish performed more behaviours on each day of the experiment than cultured or transgenic fish (note that ties, or scores of zero, were not included in the analyses resulting in variation in the sample sizes used in the tests). Sign tests are conservative as they assess the direction of the difference between treatments rather than the magnitude of the difference. Experimental arenas were assessed together to increase statistical power. We confined our behavioural analyses to days when fish from both strains were present in the arena (i.e. before one of the competing strains was no longer present in the spawning arenas due to natural mortalities) and mean behavioural scores from the spawning arenas were corrected for the number of fish from each strain that were alive each day. Observed competitive reproductive success data between strains was compared against the values expected if fish were mating randomly using chi squared tests. Sperm velocity and longevity were log-transformed prior to analyses and sperm density was arcsine square root transformed to account for percentage data (Zar, 1999). Sperm characteristics were compared between wild and transgenic males using two-sample t-tests. Pearson's product-moment correlations were used to investigate correlations between sperm characteristics.

Each of the competitive spawning experiments was replicated twice. However, when examining survival times, phenotypes, and physiology we performed our analyses on the level of the individual fish (as these could be identified reliably at the time of their removal from the experiments) to increase statistical power. In these models we included the mating arena (A and B) as a random blocking effect. For each test, non-significant interaction terms were removed from the model and we present the results from the reduced model. We refrained from statistically examining differences between the two experiments because the experiments were performed in separate years and we were therefore unable to distinguish year effects from treatment effects in our analyses.

\section{Results}

\subsection{Part I: competitive spawning experiments}

\subsubsection{Experiment 1: cultured vs. wild coho salmon}

We detected a significant interaction in body mass between sex and strain (two-way ANOVA, $\mathrm{F}_{1,27}=4.08, \mathrm{p}=0.05$, Table 1 ). Overall, cultured fish were smaller than wild fish (strain effect: $F_{1,27}=210.73$, $\mathrm{p}<0.0001)$, but the significant effect of sex in the model $\left(\mathrm{F}_{1,27}=4.59\right.$, $\mathrm{p}=0.04$ ) was driven by wild males being significantly larger than wild females, while cultured males and females did not differ in body mass (Table 1 ). Neither sex (proportional hazard model, $\chi^{2}=2.01$, $\mathrm{n}=32, \mathrm{p}=0.16)$ nor arena effects $\left(\chi^{2}=0.02, \mathrm{n}=32, \mathrm{p}=0.89\right)$ influenced survivorship. Cultured fish (mean \pm SE, $10.5 \pm 0.52$ days) did not survive longer than wild fish $\left(7.7 \pm 0.80\right.$ days, $\chi^{2}=2.60$, $\mathrm{n}=32, \mathrm{p}=0.11$ ).

Matings between wild males and females accounted for 86.1$88.6 \%$ of the offspring sampled while cultured fish sired $11.4-13.9 \%$ of

\section{Table 1}

Mean $( \pm$ SE) body mass of cultured and wild coho used in Experiment 1 and transgenic and wild coho used in Experiment 2. Different superscript letters represent significant differences between strains and sexes based on two-way ANOVAs.

\begin{tabular}{llll}
\hline & Strain & Sex & Body mass $(\mathrm{kg})$ \\
\hline Experiment 1 & Cultured & Male & $0.68 \pm 0.05^{\mathrm{a}}$ \\
& Cultured & Female & $0.67 \pm 0.04^{\mathrm{a}}$ \\
& Wild & Male & $2.28 \pm 0.25^{\mathrm{C}}$ \\
& Wild & Female & $1.66 \pm 0.11^{\mathrm{b}}$ \\
Experiment 2 & Transgenic & Male & $3.59 \pm 0.16^{\mathrm{A}}$ \\
& Transgenic & Female & $3.70 \pm 0.23^{\mathrm{A}}$ \\
& Wild & Male & $3.48 \pm 0.17^{\mathrm{A}}$ \\
& Wild & Female & $2.29 \pm 0.17^{\mathrm{B}}$ \\
\hline
\end{tabular}

offspring (Table 2). Wild fish sired significantly more offspring than would have been expected from random mating $\left(\chi^{2}\right.$ test, arena A: $\chi^{2}=3046.99, \mathrm{p}<0.0001$, arena $\left.\mathrm{B}: \chi^{2}=3077.20, \mathrm{p}<0.0001\right)$. Every wild fish successfully sired offspring, while only half of the cultured females in arenas A and B sired offspring and 2 cultured males (arena A) and 3 cultured males (arena B) sired offspring. The least frequent class of progeny was derived from matings involving cultured males.

Wild males also performed more courtship $(z=3.58, n=20$, $\mathrm{p}<0.001)$ and aggressive $(\mathrm{z}=2.68, \mathrm{n}=20, \mathrm{p}=0.007)$ behaviours than cultured males (Fig. 1). Wild females performed more aggressive behaviours than cultured females $(z=3.0, n=16, p=0.003)$, but there was no statistical difference in courtship behaviours performed by each strain ( $\mathrm{z}=1.51, \mathrm{n}=11, \mathrm{p}=0.13$, Fig. 1 ).

\subsubsection{Experiment 2: transgenic vs. wild coho salmon}

We detected a significant interaction in body mass between sex and strain $\left(F_{1,27}=13.42, p<0.001\right.$, Table 1$)$. The significant effect of sex $\left(F_{1,27}=11.0, p<0.01\right)$ and strain $\left(F_{1,27}=17.43, p<0.001\right)$ in our model was due to wild females being smaller than wild males and all transgenic fish, which did not differ from one another. There was no effect of sex $\left(\chi^{2}=0.50, \mathrm{n}=32, \mathrm{p}=0.48\right)$, arena effects $\left(\chi^{2}=0.01\right.$, $\mathrm{n}=32, \mathrm{p}=0.93$ ) or strain (wild fish: $4.1 \pm 0.40$ days, transgenic fish: $5.5 \pm 0.83$ days, $\chi^{2}=2.73, \mathrm{n}=32, \mathrm{p}=0.10$ ) on survivorship.

Matings between wild parents generated $94.4-97.8 \%$ of all offspring sampled, while transgenic fish sired $2.25-5.6 \%$ of offspring when we considered all crosses involving a transgenic parent (Table 2). Thus, crosses between wild males and females occurred more frequently than would have been expected if random mating occurred among all fish (arena $\mathrm{A}: \chi^{2}=1125.83, \mathrm{p}<0.0001$, arena $\left.\mathrm{B}: \chi^{2}=899.94, \mathrm{p}<0.0001\right)$. In arena $\mathrm{A}$, all transgenic progeny were produced from a single mating between a transgenic male and a wild female. In arena B, three transgenic males successfully sired offspring; one transgenic male mated with a wild female and two transgenic males mated with the same transgenic female.

Wild fish performed more courtship behaviours than transgenic fish (males: $\mathrm{z}=2.45, \mathrm{n}=6, \mathrm{p}=0.01$; females: $\mathrm{z}=2.33, \mathrm{n}=9$,

\section{Table 2}

The percentage of offspring generated from possible parental cross between cultured males (CM) and females (CF) and wild males (WM) and females (WF) in Experiment 1 and transgenic males (TM) and females (TF) and wild males (WM) and females (WF) in Experiment 2. Data from experimental replicate arenas A and B are presented. These data reflect that transgenic fish were hemizygous for the transgene.

\begin{tabular}{|c|c|c|c|c|c|}
\hline & Arena & $\begin{array}{l}\mathrm{WM} \times \mathrm{WF} \\
(\%)\end{array}$ & $\begin{array}{l}\mathrm{WM} \times \mathrm{CF} \\
(\%)\end{array}$ & $\begin{array}{l}\mathrm{CM} \times \mathrm{WF} \\
(\%)\end{array}$ & $\begin{array}{l}\mathrm{CM} \times \mathrm{CF} \\
(\%)\end{array}$ \\
\hline \multirow{3}{*}{$\begin{array}{l}\text { Experiment 1: } \\
\text { cultured vs. wild }\end{array}$} & A & 88.61 & 3.70 & 7.47 & 0.21 \\
\hline & B & 86.11 & 8.28 & 0.07 & 5.54 \\
\hline & Arena & $\begin{array}{l}\mathrm{WM} \times \mathrm{WF} \\
(\%)\end{array}$ & $\begin{array}{l}\mathrm{WM} \times \mathrm{TF} \\
(\%)\end{array}$ & $\begin{array}{l}\mathrm{TM} \times \mathrm{WF} \\
(\%)\end{array}$ & $\begin{array}{l}\mathrm{TM} \times \mathrm{TF} \\
(\%)\end{array}$ \\
\hline \multirow{2}{*}{$\begin{array}{l}\text { Experiment 2: } \\
\text { transgenic vs. wild }\end{array}$} & A & 97.75 & 0 & 1.00 & 1.25 \\
\hline & B & 94.39 & 0 & 5.61 & 0 \\
\hline
\end{tabular}



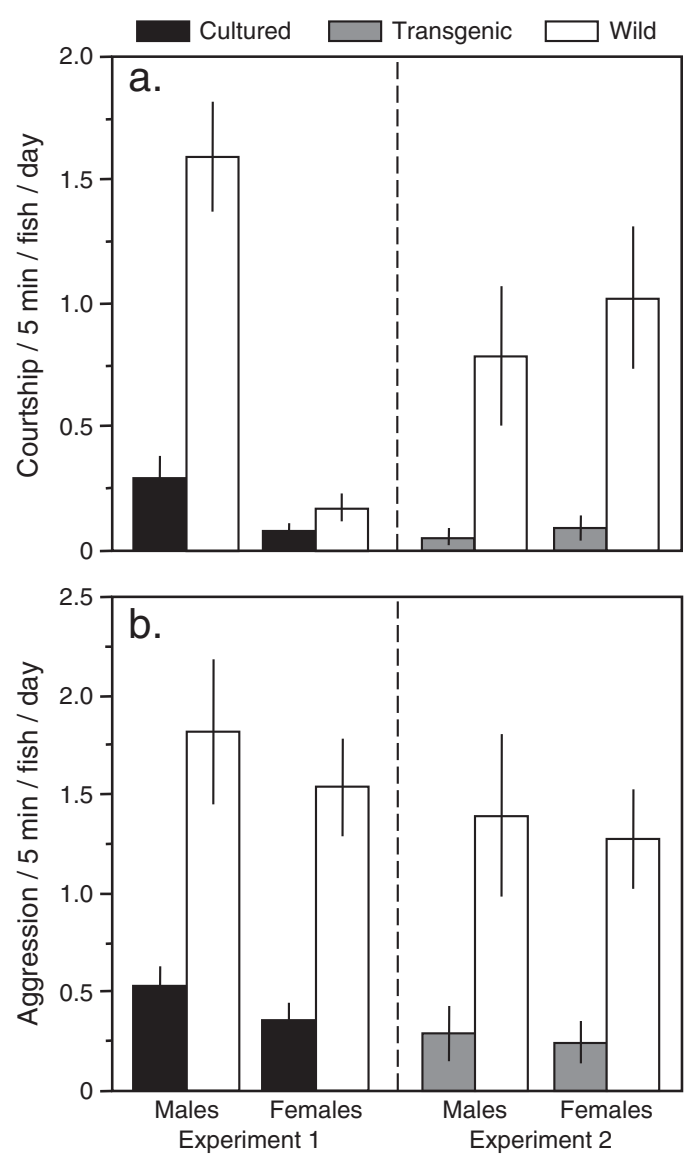

Fig. 1. Mean behavioural scores per 5 min observation period per fish per day ( \pm SE) for (a) courtship and (b) aggressive behaviours of cultured (black bars), transgenic (grey bars) and wild (white bars) fish in Experiment 1 and Experiment 2. Behavioural scores are presented as the mean number of behaviours performed over the course of the experiment when data from both experimental tanks are combined.

$p=0.02$, Fig. 1). Wild females performed more aggressive behaviours than transgenic females $(z=3.16, n=10, p=0.002)$, while there was a non-significant trend suggesting that wild males performed more aggressive behaviours than transgenic males $(\mathrm{z}=1.89, \mathrm{n}=7$, $\mathrm{p}=0.06$, Fig. 1).

\subsection{Part II: sperm quality of transgenic and wild salmon}

Wild salmon had denser ejaculates ( $\mathrm{t}$-test, $\mathrm{t}_{13}=2.53, \mathrm{p}=0.02$ ), faster swimming sperm $\left(\mathrm{t}_{13}=2.55, \mathrm{p}=0.02\right)$, and longer-lived sperm $\left(t_{13}=3.30, p=0.006\right)$ than transgenic males (Fig. 2).

\section{Discussion}

The results of the present study indicate that cultured $\mathrm{GH}$ transgenic coho are inferior to wild coho when competing for reproductive opportunities. The monopolization of reproduction exhibited by wild coho (siring $>94 \%$ offspring) is likely the result of a combination of factors. First, transgenic coho had limited reproductive opportunities, as they performed less aggressive behaviour (an effect that was more pronounced in females than males) and fewer courtship behaviours than wild coho. Transgenic salmon may also not have been preferred as mates, as they have reduced development of secondary sexual characteristics (e.g. kype and red colouration) that typify sexually mature wild coho (Bessey et al., 2004). Second, when transgenic males did participate in spawning events (siring up to $5.6 \%$ of offspring), their reproductive output was likely reduced because they had fewer and slower sperm in their ejaculate. Males
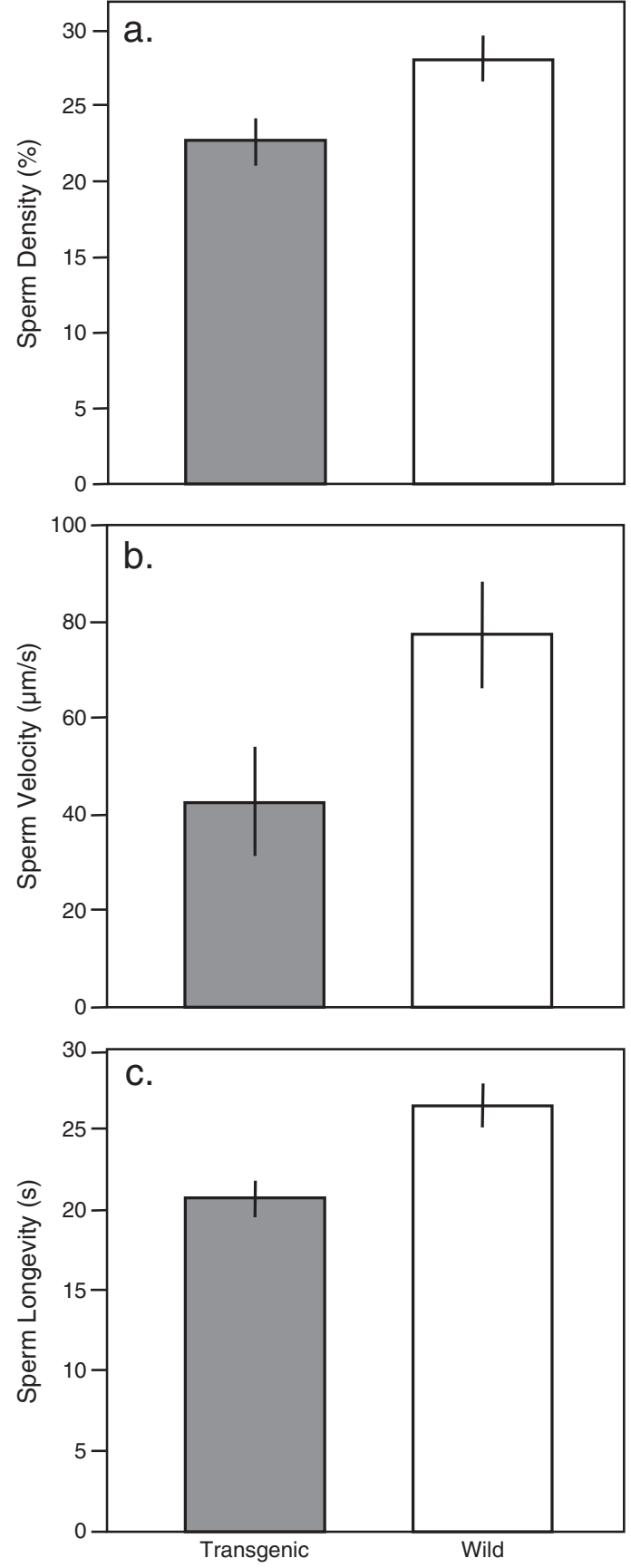

Fig. 2. Comparisons of the mean ( \pm SE) values of (a) sperm density, (b) sperm velocity (VCL) and (c) sperm longevity between wild and transgenic male coho.

who ejaculate greater numbers of sperm and faster swimming sperm are more likely to fertilize eggs in many species (Snook, 2005), including salmonids (Hoysak and Liley, 2001; Gage et al., 2004; Liljedal et al., 2008). However, it is important to remember that ejaculate quality may have been influenced by differences in the rearing environments and dietary histories experience by transgenic and wild males, particularly as the expression of ejaculate traits can be condition dependent (Helfenstein et al., 2010). Thus, our results may only be representative of the first generation of a transgenic invasion. Nevertheless, transgenic males who enter a marine environment from a laboratory facility and successfully spawn may be unsuccessful in fertilizing a large proportion of a clutch when their ejaculates compete with those of wild males. This suggests that transgenic coho may be at a mating disadvantage during both precopulatory and postcopulatory competition. 
As with any study where animals are reared in laboratory environments that influence behaviour and physiology, we are unable to directly assess if our results are due to environmental effects rather than resulting from differences between salmon strains. Sexually mature laboratory-reared non-transgenic coho are smaller than wild fish (Devlin et al., 2004a; Bessey et al., 2004). Because larger salmon are more successful when breeding (Fleming and Gross, 1993; Fleming, 1998) the reduced body size of cultured fish may explain why they were reproductively disadvantaged when competing against wild fish. However, if body size alone determined reproductive success, one might expect that $\mathrm{GH}$ transgenic fish would perform better than smaller cultured fish when in competition with wild fish. Yet, our results show the opposite pattern. When competing against wild fish, cultured fish sired more than twice as many offspring as transgenic fish, possibly because the smaller body size of cultured males allowed them to obtain a closer position to females during oviposition, thereby affording cultured males a reproductive advantage by using sneak mating behaviours (sensu Stoltz and Neff, 2006). Therefore, transgenic salmon reproductive success was lower than expected if large body size was the only factor determining reproductive success. Instead, our data suggests that GH transgenesis negatively affects reproductive behaviours and breeding success in transgenic salmon, beyond effects arising from rearing in a culture environment.

One major objective of ecological risk assessment research is to estimate the fitness of transgenics animals, which depends on many factors affecting survival and reproduction. The few studies that have investigated the competitive reproductive success of transgenic animals in competition with non-transgenic animals have found mixed results. For example, transgenic male Japanese medaka (Oryzias latipes) and channel catfish (Ictalurus punctatus) outcompete non-transgenic fish raised in the same culture conditions (Dunham et al., 1995; Howard et al., 2004), whereas wild coho salmon out-compete GH transgenic coho in paired spawnings (Bessey et al., 2004) and in semi-natural systems that allow mate choice and competition (this study). Extrapolating these results to a wider ecological context is difficult as an animal's phenotype, behaviour and physiology are quite plastic and influenced both by their genotype and environment, as well as their interactions $(G \times E)$. For example, in nature, hybrid offspring generated from wild and farmed salmon exhibit dramatically different growth rates and reproductive behaviours (McGinnity et al., 2003; Naylor et al., 2005; Weir et al., 2005), which can have important implications for the development of alternative male reproductive tactics (see below). Consequently, biological responses of laboratory-reared transgenic animals may not accurately predict outcomes as they would occur in nature (Devlin et al., 2004b, 2006; Sundström et al., 2007).

In many salmon species, there are two male reproductive tactics; large anadromous (ocean-going) males, who court and defend females, and small sneaker males, who remain in freshwater streams and develop precociously. The energy stores (i.e. lipids) sequestered by an individual can influence the maturation of sneaker males (Rowe et al., 1991; Arndt, 2000) and juvenile male salmon above a size threshold value are more likely to adopt a sneaking reproductive tactics (Aubin-Horth and Dodson, 2004). Juvenile GH transgenic salmon have enhanced appetites and feeding motivation (Abrahams and Sutterlin, 1999; Devlin et al., 1999, 2004b; Sundström et al., 2004), allowing them to sequester greater energy stores and thus grow faster than non-transgenic salmon in the laboratory (albeit much reduced in semi-natural stream environments; Sundström et al., 2007). Thus, male progeny generated from transgenic salmon may be more likely to develop into sneaker males under some conditions. Therefore, introgression of a transgene into wild populations may be further accentuated by the shortened maturation age of precociously developing males if transgenic salmon escaped into nature (Garant et al., 2003; Howard et al., 2004). Currently, there is no evidence that transgenic coho are likely to develop into mature sneakers; however, since these fish mature at 2 years of age (rather than the normal 3 years), they all could be said to be maturing precociously, albeit at an approximately normal adult size. In species such as chinook or Atlantic salmon, which normally have precociously maturing sneakers (and also show significant growth enhancement by GH transgenesis; Du et al., 1992; Devlin et al., 1995), effects of early maturation may have more significant effects on transgene transmission in populations (Garant et al., 2003).

\section{Conclusions and caveats}

Our results suggest that the reduction in reproductive behaviours and sperm quality of transgenic coho put them at a reproductive disadvantage when competing against wild coho. However, since transgenic offspring exhibit reduced survival compared with wild offspring (Devlin et al., 2004a) the total number of eggs sired by transgenic fish in this study is likely to be greater than what was revealed by our molecular analyses. Moreover, because the experiments were performed in different years we are not able to distinguish between treatment and year effects in our analyses. However, despite these caveats, it seems clear from our experiments that the competitive reproductive ability of cultured GH transgenic fish is not superior to wild fish; a result which is particularly relevant as theoretical models suggest that larger transgenic organisms may have an advantage during mate choice and intrasexual competition (Muir and Howard, 1999). However, even the modest measure of reproductive success achieved by cultured GH transgenic salmon in our study may have important ecological consequences if this occurred in the wild and allowed the establishment of transgenes in natural populations (Muir and Howard, 1999). Transgenic animals experiencing natural rearing conditions throughout their life history are likely to have an altered capacity to breed with wild-type fish in nature as compared to escaped cultured animals. If transgenic salmon were to breed in the wild and have their phenotypes shaped by nature, their reproductive success may be superior to that which we have measured for cultured fish, and hence ecological effects may also be significantly affected. Thus, in order to assess fully the ecological risk associated with transgenic salmon entering an ecosystem, researchers must gain a robust understanding of how $\mathrm{G} \times \mathrm{E}$ interactions influence the reproductive physiology and behaviours of transgenic salmon.

\section{Acknowledgments}

We thank Marc D'Andrade, Mitch Uh, and Ben Goh for assisting with the experimental set up and analyses. Support for this research was provided by the Natural Sciences and Engineering Research Council for JLF and the Canadian Regulatory System for Biotechnology to RHD.

\section{References}

Abrahams, M.V., Sutterlin, A., 1999. The foraging and antipredator behaviour of growthenhanced transgenic Atlantic salmon. Animal Behaviour 58, 933-942.

Arndt, S.K.A., 2000. Influence of sexual maturity on feeding, growth and energy stores of wild Atlantic salmon parr. Journal of Fish Biology 57, 589-596.

Aubin-Horth, N., Dodson, J.J. 2004. Influence of individual body size and variable thresholds on the incidence of a sneaker male reproductive tactic in Atlantic salmon. Evolution 58, 136-144.

Berejikian, B.A., Tezak, E.P., Park, L., Schroder, S.L., Beall, E.P., LaHood, E., 2001. Male competition and breeding success in captively reared and wild coho salmon (Oncorhynchus kisutch). Canadian Journal of Fisheries and Aquatic Sciences 58, 804-810.

Bessey, C., Devlin, R.H., Liley, N.R., Biagi, C.A., 2004. Reproductive performance of growth-enhanced transgenic coho salmon. Transactions of the American Fisheries Society $133,1205-1220$.

Burner, C.J., 1951. Characteristics of spawning nests of Columbia River salmon. Fishery Bulletin 61, 97-110. 
Devlin, R.H., Donaldson, E.M., 1992. Containment of genetically altered fish with emphasis on salmonids. In: Hew, C.L., Fletcher, G.L. (Eds.), Transgenic Fish. World Scientific Press, Singapore, Singapore (Singapore), pp. 229-265.

Devlin, R.H., Yesaki, T.Y., Biagi, C.A., Donaldson, E.M., Swanson, P., Chan, W.K., 1994 Extraordinary salmon growth. Nature 371, 209-210.

Devlin, R.H., Johnsson, J.I., Smailus, D.E., Biagi, C.A., Joensson, E., Bjoernsson, B.T., 1999. Increased ability to compete for food by growth hormone-transgenic coho salmon Oncorhynchus kisutch (Walbaum). Aquaculture Research 30, 479-482.

Devlin, R.H., Biagi, C.A., Yesaki, T.Y., 2004a. Growth, viability and genetic characteristics of GH transgenic coho salmon strains. Aquaculture 236, 607-632.

Devlin, R.H., D'Andrade, M., Uh, M., Biagi, C.A., 2004b. Population effects of growth hormone transgenic coho salmon depend on food availability and genotype by environment interactions. Proceedings of the National Academy of Sciences of the United States of America 101, 9303-9308.

Devlin, R.H., Sundström, L.F., Muir, W.M., 2006. Interface of biotechnology and ecology for environmental risk assessment of transgenic fish. Trends in Biotechnology 24, 89-97.

Du, S.J., Gong, Z., Fletcher, G.L., Shears, M.A., King, M.J., Idler, D.R., Hew, C.L., 1992 Growth enhancement in transgenic Atlantic salmon by use of an "all fish" chimeric growth hormone gene construct. Biotechnology 10, 176-181.

Dunham, R.A., Chen, T.T., Powers, D.A., Nichols, A., Argue, B., Chitmanat, C., 1995 Predator avoidance, spawning, and foraging ability of transgenic channel catfish with rainbow trout growth hormone gene. In: Levin, M., Grim, C., Angle, J.S. (Eds.), Biotechnology Risk Assessment: Proceedings of the Biotechnology Risk Assessment Symposium, June 6-8, 1995. TechniGraphix, Reston, VA, USA, pp. 127-139.

Farrell, A.P., Bennett, W., Devlin, R.H., 1997. Growth-enhanced transgenic salmon can be inferior swimmers. Canadian Journal of Zoology 75, 335-337.

Fleming, I.A., 1998. Pattern and variability in breeding system of Atlantic salmon (Salmo salar), with comparisons to other salmonids. Canadian Journal of Fisheries and Aquatic Sciences 55, 59-76.

Fleming, I.A., Gross, M.R., 1993. Breeding success of hatchery and wild coho salmon (Oncorhynchus kisutch) in competition. Ecological Applications 3, 230-245.

Fleming, I.A., Hindar, K., Mjolnered, I.B., Jonsson, B., Balstad, T., Lamberg, A., 2000. Lifetime success and interactions of farm salmon invading a native population. Proceedings of the Royal Society. Series B: Biological Sciences 267, 1517-1523.

Fu, C., Cui, Y., Hung, S.S.O., Zhu, Z., 1998. Growth and feed utilization by F4 human growth hormone transgenic carp fed diets with different protein levels. Journal of Fish Biology 53, 115-129.

Gage, M.J.G., MacFarlane, C., Yeates, S., Shackleton, R., Parker, G.A., 2002. Relationships between sperm morphometry and sperm motility in the Atlantic salmon. Journal of Fish Biology 61, 1528-1539.

Gage, M.J.G., Macfarlane, C.P., Yeates, S., Ward, R.G., Searle, J.B., Parker, G.A., 2004. Spermatozoal traits and sperm competition in Atlantic salmon: relative velocity is the primary determinant of fertilization success. Current Biology 14, 44-47.

Garant, D., Fleming, I.A., Einum, S., Bernatchez, L., 2003. Alternative male life-history tactics as potential vehicles for speeding introgression of farm salmon traits into wild populations. Ecology Letters 6, 541-549.

Helfenstein, F., Losdat, S., Moller, A.P., Blount, J.D., Richner, H., 2010. Sperm of colourful males are better protected against oxidative stress. Ecology Letters 13, 213-222.

Hindar, K., Fleming, I.A., McGinnity, P., Diserud, A., 2006. Genetic and ecological effect of salmon farming on wild salmon: modelling from experimental results. ICES Journal of Marine Science 63, 1234-1247.

Howard, R.D., DeWoody, J.A., Muir, W.M., 2004. Transgenic male mating advantage provides opportunity for Trojan gene effect in a fish. Proceedings of the National Academy of Sciences of the United States of America 101, 2934-2938.

Hoysak, D.J., Liley, N.R., 2001. Fertilization dynamics in sockeye salmon and a comparison of sperm from alternative male phenotypes. Journal of Fish Biology $58,1286-1300$

Jhingan, E., Devlin, R.H., Iwama, G.K., 2003. Disease resistance, stress response and effects of triploidy in growth hormone transgenic coho salmon. Journal of Fish Biology 63, 806-823.

Kapuscinski, A., Hallerman, E., 1991. Implications of introduction of transgenic fish into natural ecosystems. Canadian Journal of Fisheries and Aquatic Sciences 48, 99-107.
Kapuscinski, A.R., Hayes, K.R., Li, S., Dana, G., 2007. Environmental Risk Assessment of Genetically Modified Organisms. : Methodologies for Transgenic Fish, Vol. 3. CABI International, Oxfordshire.

Liljedal, S., Rudolfsen, G., Folstad, I., 2008. Factors predicting male fertilization success in an external fertilizer. Behavioral Ecology and Sociobiology 62, 1805-1811.

Martinez, R., Estrada, M.P., Berlanga, J., Guillén, I., Hernández, O., Cabrera, E., Pimentel, R., Morales, R., Herrera, F., Morales, A., Piña, J.C., Abad, Z., Sánchez, V., Melamed, P., Lleonart, R., de la Fuente, J., 1996. Growth enhancement in transgenic tilapia by ectopic expression of tilapia growth hormone. Molecular Marine Biology and Biotechnology 5, 62-70.

McGinnity, P., Prodöhl, P., Ferguson, A., Hynes, R., Ó Maoiléidigh, N., Baker, N., Cotter, D. O'Hea, B., Cooke, D., Rogan, G., Taggart, J., Cross, T., 2003. Fitness reduction and potential extinction of wild populations of Atlantic salmon, Salmo salar, as a result of interactions with escaped farm salmon. Proceedings of the Royal Society of London B: Biological Sciences 270, 2443-2450.

Muir, W.M., Howard, R.D., 1999. Possible ecological risks of transgenic organism release when transgenes affect mating success: sexual selection and Trojan gene hypothesis. Proceedings of the National Academy of Sciences of the United States of America 96, 13853-13856.

Naylor, R., Hindar, K., Fleming, I.A., Goldburg, R., Williams, S., Volpe, J., Whoriskey, F., Eagle, J., Kelso, D., Mangel, M., 2005. Fugitive salmon: assessing the risk of escaped fish from net-pen aquaculture. Bioscience 55, 427-437.

Pitcher, T.E., Rodd, F.H., Rowe, L., 2007. Sexual colouration and sperm traits in guppies. Journal of Fish Biology 70, 165-177.

Pursel, V.G., Pinkert, C.A., Miller, K.F., Bolt, D.J., Campbell, R.G., Palmiter, R.D., Brinster, R. L., Hammer, R.E., 1989. Genetic engineering of livestock. Science 244, 1281-1288.

Rahman, M.A., Mak, R., Ayad, H., Smith, A., Maclean, N., 1998. Expression of a novel piscine growth hormone gene results in growth enhancement in transgenic tilapia (Oreochromis niloticus). Transgenic Research 7, 357-369.

Rexroad, C.E., Palti, Y., 2003. Development of ninety-seven polymorphic microsatellite markers for rainbow trout. Transactions of the American Fisheries Society 132, 1214-1221.

Rexroad, C.E., Coleman, R.L., Martin, A.M., Hershberger, W.K., Killefer, J., 2001. Thirtyfive polymorphic microsatellite markers for rainbow trout (Oncorhynchus mykiss). Animal Genetics 32, 283-319.

Rowe, D.K. Thorpe, J.E. Shanks, A.M., 1991. The role of fat stores in the maturation of male Atlantic salmon (Salmo salar) parr. Canadian Journal of Fisheries and Aquatic Sciences 48, 405-413.

Small, M.P., Withler, R.E., Beacham, T.D., 1998. Population structure and stock identification of British Columbia coho salmon, Oncorhynchus kisutch, based on microsatellite DNA variation. Fisheries Bulletin 96, 843-858.

Snook, R.R., 2005. Sperm in competition: not playing by the numbers. Trends in Ecology and Evolution 20, 46-53.

Snow, A.A., Andow, D.A., Gepts, P., Hallerman, E.M., Power, A., Tiedje, J.M., Wolfenbarger, L.L., 2005. Genetically engineered organisms and the environment: current status and recommendations. Ecological Applications 15, 377-404.

Stoltz, J.A., Neff, B.D., 2006. Male size and mating tactic influence proximity to females during sperm competition in bluegill sunfish. Behavioral Ecology and Sociobiology 59, 811-818.

Sundström, L.F., Lõhmus, M., Devlin, R.H., Johnsson, J.I., Biagi, C.A., Bohlin, T., 2004. Feeding on profitable and unprofitable prey: comparing behaviour of growth-enhanced transgenic and normal coho salmon (Oncorhynchus kisutch). Ethology 110, 381-396.

Sundström, L.F., Lõhmus, M., Tymchuk, W.E., Devlin, R.H., 2007. Gene-environment interactions influence ecological consequences of transgenic animals. Proceedings of the National Academy of Sciences of the United States of America 104, 3889-3894.

Tatar, M., 2000. Transgenic organisms in evolutionary ecology. Trends in Ecology and Evolution 15, 207-211.

Venugopal, T., Anathy, V., Kirankumar, S., Pandian, T.J., 2004. Growth enhancement and food conversion efficiency of transgenic fish Labeo rohita. Journal of Experimental Zoology 301, 477-490.

Weir, L.K., Hutchings, J.A., Fleming, I.A., Einum, S., 2005. Spawning behaviour and success of mature male Atlantic salmon (Salmo salar) parr of farmed and wild origin. Canadian Journal of Fisheries and Aquatic Sciences 62, 1153-1160.

Zar, J.H., 1999. Biostatistical Analysis, 4th ed. Prentice Hall, Upper Saddle River, NJ 